\title{
Genetic Polymorphisms in IL-10 Promoter Are Associated With Smoking and Prostate Cancer Risk in African Americans
}

\author{
MUNEER ABBAS ${ }^{1,2}$, TSHELA MASON $^{2}$, ALIZA IBAD $^{2}$, MOZNA KHRAIWESH $^{3}$, \\ VICTOR APPREY ${ }^{2}$, YASMINE KANAAN ${ }^{1}$, BRADFORD WILSON ${ }^{2}$, GEORGIA DUNSTON ${ }^{1}$, \\ LUISEL RICKS-SANTI ${ }^{4}$ and HASSAN BRIM ${ }^{5}$ \\ ${ }^{1}$ Department of Microbiology, Howard University, Washington, DC, U.S.A.; \\ ${ }^{2}$ The National Human Genome Center, Howard University, Washington, DC, U.S.A.; \\ ${ }^{3}$ Experimental Therapeutics Branch, Walter Reed Army Institute of Research, Silver Spring, MD, U.S.A.; \\ ${ }^{4}$ Cancer Research Center, Hampton University, Hampton, VA, U.S.A.; \\ ${ }^{5}$ Department of Pathology, Howard University College of Medicine, Washington, DC, U.S.A.
}

\begin{abstract}
Background/Aim: Even though prostate cancer (PCa) has good prognosis, there is a discrepancy in the risk among ethnic groups, with high morbidity in African American men. Single nucleotide polymorphisms (SNPs) in interleukin 10 (IL-10) have been associated with inflammation and cancer risk. We investigated the association of five SNPs in the IL-10 promoter with clinical features such as Gleason score and smoking. Materials and Methods: A total of 413 DNA samples were obtained from a nested casecontrol study of African American males who were genotyped for 5 SNPs utilizing pyrosequencing. Multiple and binary logistic regression models were applied to analyze the clinical and genotypic data. Results: rs12122923 and rs1800871 were associated with PCa risk. Smoking was also found to increase the risk of PCa by 1.6-fold. rs1800893 was found to be associated with lower grades for prostate cancer. Conclusion: $I L-10$ promoter polymorphisms might be a risk factor for $\mathrm{PCa}$ development in smoking subjects and PCa progression.
\end{abstract}

Prostate cancer (PCa) is one of the most commonly diagnosed forms of cancer among men in the United States. As per Surveillance Epidemiology and End Results Program (SEER), 180,890 new cases were estimated in 2016, of

This article is freely accessible online.

Correspondence to: Muneer Abbas, Department of Microbiology, College of Medicine, Howard University, 520 W. Street, NW, Washington, DC, 20059, U.S.A. Tel: +1 2028063396, Fax: +1 2029863972, e-mail: m_abbas@howard.edu

Key Words: Single nucleotide polymorphisms, interleukin 10, prostate cancer, smoking, inflammation, African-American. which 26,120 resulted in death. Even though PCa has a good prognosis due to early detection, there is a disparity in the risk of developing PCa among ethnic groups, specifically, the prevalence and morbidity rates are higher in AfricanAmerican men and men of African descent than in most other populations $(1,2)$. The well-established risk factors that contribute to $\mathrm{PCa}$ include age, ethnicity, family history, genetic predisposition, diet and environmental factors (3). However, the molecular mechanisms underlying the development and progression of this malignancy remain poorly understood, and if investigated, could possibly lead to closing the disproportionate gap in prognosis and mortality of PCa among African Americans.

New advances in molecular and genetic studies have demonstrated a causal relationship between chronic infection, chronic inflammation, and $\mathrm{PCa}(4,5)$. The hallmarks of cancer, as described by Hananan and Weinberg, 2011, include sustaining proliferative signaling, evading growth suppressors, resisting cell death, enabling replicative immortality, inducing angiogenesis, and activating invasion and metastasis where inflammation purportedly expedites these cancer characteristics (6). Also, chronic inflammation has been hypothesized to be a cause of PCa where it can contribute to carcinogenesis during disease initiation and subsequent stages $(7,8)$.

Interleukin-10 (IL-10), which is an anti-inflammatory cytokine, is produced by $\mathrm{TH} 2$ cells and is known as a cytokine synthesis inhibitory factor that has a censorious effect in the regulation of inflammatory responses which may contribute to angiogenesis and survival of tumor cells (9). Particularly, it can inhibit the production of interleukin2 , interleukin-3, interferon $\gamma$, and granulocyte monocytecolony stimulating factor by $\mathrm{T}$ helper cells. Differential production of this cytokine has been associated with singlenucleotide polymorphisms (SNPs) in the promoter region 
Table I. Characteristics of the study population.

\begin{tabular}{lcc}
\hline & $\begin{array}{c}\text { Cases } \\
(\mathrm{n}=242)\end{array}$ & $\begin{array}{c}\text { Controls } \\
(\mathrm{n}=177)\end{array}$ \\
\hline Age (Years) & & \\
$\quad$ Mean (SD) & $69.02(9.67)$ & $57.5(11.32)$ \\
Smoking N (\%) & $101(41.7)$ & $47(26.6)$ \\
Yes & $80(33.06)$ & $59(33.3)$ \\
No & $61(25.24)$ & $71(40.1)$ \\
Missing & $28(11.6)$ & $8(4.5)$ \\
Vitamin D N (\%) & $99(40.9)$ & $30(16.9)$ \\
Severe deficiency $<10$ & $30(12.4)$ & $8(4.5)$ \\
Low [10, 25) & $2(0.8)$ & 0 \\
Optimal [25, 80) & $83(34.3)$ & $131(74.1)$ \\
Very high $\geq 80$ & & \\
Missing & $18(7.4)$ & \\
Gleason score N (\%) & $114(47.15)$ & \\
Grade I [1-4] & $25(10.33)$ & \\
Grade II [5-7] & $85(35.12)$ & \\
Grade III [8-10] & & \\
Missing &
\end{tabular}

(10-12). The involvement of IL-10 polymorphisms in cancer development is controversial as this pleiotropic cytokine has both immune-suppressive and anti-angiogenic properties.

Variations in IL-10 have been associated with PCa risk in many studies (13-16) that showed a reduced level of IL-10, having been associated with the presence of IL10-1082A/$819 \mathrm{~T} /-592 \mathrm{~A}$ haplotype on the IL-10 gene promoter as well as increased risk of cancer in several populations (17). Therefore, we investigated the association of promoter variations in IL-10 with the incidence of PCa using a nested case-control study of men of African descent.

\section{Materials and Methods}

Study population. The study population consisted of $242 \mathrm{PCa}$ patients and 177 controls that were recruited at Howard University Hospital Urology department and cancer center screening programs. PCa patients were recruited from Washington DC area through the Division of Urology and PCa screening clinic at the Howard University Cancer Center, while the controls were recruited from volunteers enrolled among individuals undergoing regular physical examinations. The following characteristics were collected from all subjects in the study: All subjects were of African descent as defined by Mason et al (5). Clinical characteristics that included Gleason grade, smoking history, and vitamin D deficiency were obtained from medical records (Table I). Individuals diagnosed with benign prostatic hyperplasia (BPH) were not considered in this analysis because studies showed that BPH does not increase or contribute to the risk of prostate cancer (4). PCa cases were diagnosed by transrectal ultrasound-guided biopsy using a standard saturation technique (18). Biopsy cores were reviewed by members of the Department of Pathology in the College of Medicine at Howard University. PCa cases were classified according to well-
Table II. IL-10 promoter region SNP information.

\begin{tabular}{lccc}
\hline SNP & $\begin{array}{c}\text { Chromosomal } \\
\text { location }\end{array}$ & $\begin{array}{c}\text { Chromosomal } \\
\text { position }\end{array}$ & $\begin{array}{c}\text { Gene } \\
\text { location }\end{array}$ \\
\hline rs1800871 & 1 & 206773289 & promoter \\
rs1800893 & 1 & 206773822 & promoter \\
rs12122923 & 1 & 206778052 & promoter \\
rs10494879 & 1 & 206778859 & promoter \\
\hline
\end{tabular}

established parameters of the Gleason Scoring System (19-22) (Table I). The study was approved by IRB and informed consent form was obtained from all participants.

SNPs selection. Interleukin-10 SNPs were obtained from the NCBI dbSNP (National Center for Biotechnology Information) database (23), and prioritized using the SNP prioritization algorithm which was developed at the Howard University-National Human Genome Center (NHGC) and by Haploview ${ }^{\circledR}$ (Haploview 3.32) (24). Based on power and sample size calculations, SNPs were chosen with minor allele frequencies (MAF) greater than $10 \%$. The frequencies were compared in European-Americans and Yoruba populations using chi-square analysis of significance to identify SNPs with differential allele frequencies ( $\triangle \mathrm{MAF})$. Greater consideration was given to SNPs found in exonic regions that resulted in nonsynonymous (missense) amino acid changes. Also, we considered SNPs located in splice junctions, promoter and 3' untranslated regions (UTRs). Based on their differential race frequencies, the following four SNPs within the IL-10 promoter region were retained for this study: rs12122923, rs1800871, rs10494879 and rs18000893 (Table II).

Genotyping. Genomic DNA was isolated from whole blood samples using the Gentra Puregene Blood Kit (Qiagen, Hilden, Germany) in accordance with the manufacturer's instructions. DNA was used for genotyping SNPs utilizing pyrosequencing. Custom primer sequences for each SNP were designed using published sequences data and then were optimized for PCR amplification using Platinum Taq DNA Polymerase High Fidelity kit (Thermo Fisher Scientific, Waltham, MA, USA). Pyrosequencing was performed in an automated Pyrosequencing instrument, PSQ96 (Pyrosequencing AB, Uppsala, Sweden). Biotinylated single-stranded DNA fragments were generated by mixing the PCR product with streptavidin-coated paramagnetic beads (Dynalbeads M280, Dynal, Norway). Pyrosequencing reactions were carried out at $25^{\circ} \mathrm{C}$, with sequencing primer, DNA polymerase (exonuclease deficient), $40 \mathrm{mU}$ apyrase, $4 \mu \mathrm{g}$ of purified luciferase $/ \mathrm{ml}, 15 \mathrm{mU}$ of recombinant ATP sulfurylase, $0.1 \mathrm{M}$ Tris-acetate ( $\mathrm{pH} 7.75), 0.5 \mathrm{mM}$ EDTA, $5 \mathrm{mM}$ Mg-acetate, $0.1 \%$ BSA, $1 \mathrm{mM}$ dithiothreitol, $10 \mathrm{uM}$ adenosine 5'phosphosulfate (APS), $0.4 \mathrm{mg}$ of poly(vinylpyrrolidone)/ml and 100 $\mu \mathrm{g}$ of D-luciferin $/ \mathrm{ml}$. Pyrosequencing software (Pyrosequencing, $\mathrm{AB})$ was used to determine and analyze single peaks in the pyrogram.

Statistical analysis. The statistical analyses were performed using the SAS/STAT ${ }^{\circledR}$ software, version 9.1 (SAS Institute Inc., Cary, NC, USA) (23). Allele frequencies in controls were tested for the HardyWeinberg equilibrium using Chi-square analysis or Fisher's exact test 
Table III. Distribution of IL-10 genotypes in cases and controls.

\begin{tabular}{|c|c|c|c|c|c|c|}
\hline IL-10 SNPs & Genotype & Frequency $(\%)$ & Cases & Controls & OR $(95 \% \mathrm{CI})$ & $p$-Value \\
\hline \multirow[t]{3}{*}{ rs 1800871} & $\mathrm{CC}$ & 37.7 & $84(34.7)$ & $74(41.8)$ & 1 & \\
\hline & $\mathrm{TC}$ & 48.9 & $122(50.4)$ & $83(46.9)$ & $1.29[0.85,1.97]$ & 0.227 \\
\hline & $\mathrm{TT}$ & 13.4 & $36(14.9)$ & $20(11.3)$ & $1.59[0.85,3.01]$ & 0.151 \\
\hline \multirow[t]{3}{*}{ rs1800893 } & $\mathrm{CC}$ & 36.5 & $86(35.5)$ & $67(37.8)$ & 1 & \\
\hline & $\mathrm{TC}$ & 46.5 & $119(49.2$ & $76(42.9)$ & $1.22[0.79,1.87]$ & 0.365 \\
\hline & TT & 17.0 & $37(15.3)$ & $34(19.3)$ & $0.84[0.48,1.49]$ & 0.567 \\
\hline \multirow[t]{3}{*}{ rs12122923 } & $\mathrm{CC}$ & 83.5 & $164(65.9)$ & $85(34.1)$ & 1 & \\
\hline & $\mathrm{TC}$ & 14.8 & $24(46.2)$ & $28(53.8)$ & $0.44[0.24,0.81]$ & 0.009 \\
\hline & $\mathrm{TT}$ & 1.7 & $3(42.9)$ & $4(57.1)$ & $0.39[0.07,1.8]$ & 0.22 \\
\hline \multirow[t]{3}{*}{ rs10494879 } & GG & 96.4 & $234(96.7)$ & $170(96.4)$ & 1 & \\
\hline & GA & 1.9 & $4(1.65)$ & $4(2.2)$ & $0.73[0.17,3.11]$ & 0.655 \\
\hline & AA & 1.7 & $4(1.65)$ & $3(1.7)$ & $0.96[0.21,4.97]$ & 0.967 \\
\hline \multicolumn{7}{|c|}{ Adjusted for smoking } \\
\hline \multirow[t]{3}{*}{ rs12122923 } & $\mathrm{CC}$ & & $164(56.9)$ & $85(34.1)$ & 1 & \\
\hline & $\mathrm{TC}$ & & $24(46.2)$ & $28(53.8)$ & $0.44[0.23,0.83]$ & 0.0110 \\
\hline & $\mathrm{TT}$ & & $3(42.9)$ & $4(57.1)$ & $1.66[1.01,2.72]$ & 0.1853 \\
\hline
\end{tabular}

when appropriate. The association between genotype, specific phenotype, and case/control status was investigated via logistic regression. Odds ratios (OR) of relative risk with $95 \%$ confidence intervals $(\mathrm{CI})$ were calculated and adjusted for age as it is a possible confounder. Two-sided $p$-values $\leq 0.05$ were considered statistically significant. For each SNP, tests using the genotypic, dominant, recessive, co-dominant, over-dominant, and log-additive genetic models were performed. Additionally, the Bonferroni test was performed to correct for multiple comparison testing and subsequent adjustments were made accordingly. Frequencies were estimated using the implementation of the EM algorithm coded into the haplostats package to test the combinatorial effects of the SNPs and haplotypes.

\section{Results}

Study population features and IL-10 SNPs distribution. For this study, 242 cases and 177 controls from the African American population were recruited. Their characteristics are depicted in Table II. The cases were generally older than controls. Indeed, the cases had a mean age of 69.02 years while controls mean age was 57.5 years. Vitamin D deficiency, whether severe or moderate was more pronounced in cases than controls. After correcting for the Bonferroni test, the $p$-value was 0.0125 . There was also a significant difference in smokers within the cohort $(41.7 \%$ in cases $v s .26 .6 \%$ in controls). Within the PCa cases, there were $18(7.4 \%), 114(47.15 \%)$ and $25(10.33 \%)$ grade I, II and III Gleason score, respectively (Table II). The 4 genotyped IL-10 promoter SNPs distribution in cases and control populations are reported in Table III.

Analysis of the SNPs associations with PCa. Each of these SNPs associations with PCa risks was examined with regard to genotype. rs12122923 was found to be associated with an approximately $50 \%$ decreased risk $[p<0.009, \mathrm{OR}=0.44(0.24-$ $0.81)$ ] for $\mathrm{PCa}$ in heterozygotes genotype of TC $(14.8 \%)$ (Table III). After adjusting for smoking, the SNP remained significant [24\%, $p=0.0110, \mathrm{OR}=0.44(0.23-0.83)]$ (Table III). The association between rs12122923 and PCa risk was further analyzed to determine the most likely model of inheritance (Table IV). CC genotype (86.8\%) in the dominant model of inheritance showed an association with PCa risk $(p=0.0374)$ providing a decreased risk $[\mathrm{OR}=0.58$ (0.34-0.97)] for developing Pca (Table IV). CC genotype for rs12122923 showed significant association which does not agree with the dominant model for that SNP, but the fact that there were few $\mathrm{T}$ Homozygotes may confirm the dominant model as more reliable. When adjusted by age, only SNP rs12122923 showed an association with increased $\mathrm{PCa}$ risk in the dominant model [T/C-T/T, OR=1.78 (1.01-3.11)] (Table V).

The associations between the SNPs and PCa risk were further analyzed once adjusted for smoking status. SNP rs12122923 remained associated with smoking in the dominant model of inheritance $[p<0.0056$, OR=0.43 (0.230.78)] (Table V). Additionally, adjusting for smoking status revealed an association between PCa risk and rs1800871 by the Log-additive model of inheritance $(p<0.03901)$. This association shows an increased risk of PCa development by 1.5-fold [OR=1.49 (1.02-2.18)] (Table VI).

When associations between the SNPs and Gleason score were analyzed, the heterozygous genotype (TC) for rs1800893 was found to be associated with lower grades for prostate cancer $(p<0.0423, \mathrm{OR}=0.24)$ (Table VII, codominant model). The SNP remained associated when adjusted by age $(p<0.053, \mathrm{OR}=0.25)$ for the heterozygous genotype (TC) (Table VII, co-dominant model adjusted by age). This association was further analyzed using the 
Table IV. Genetic association between rs 12122923 and PCa.

\begin{tabular}{|c|c|c|c|c|c|}
\hline Model & Genotype & Cases $(\%)$ & Controls $(\%)$ & OR $(95 \% \mathrm{CI})$ & $p$-Value \\
\hline \multirow{3}{*}{ Co-dominant } & $\mathrm{CC}$ & $210(86.8)$ & $140(79.1)$ & 1.0 & \multirow[t]{3}{*}{0.11} \\
\hline & $\mathrm{TC}$ & $29(12)$ & 33 (18.6) & $0.59[0.34,1.01]$ & \\
\hline & $\mathrm{TT}$ & $3(1.2)$ & $4(2.3)$ & $0.5[0.11,2.27]$ & \\
\hline \multirow[t]{2}{*}{ Dominant } & $\mathrm{CC}$ & $210(86.8)$ & $140(79.1)$ & 1.0 & \multirow[t]{2}{*}{0.0374} \\
\hline & $\mathrm{TC}, \mathrm{TT}$ & $32(13.2)$ & $37(20.9)$ & $0.58[0.34,0.97]$ & \\
\hline \multirow[t]{2}{*}{ Recessive } & $\mathrm{CC}, \mathrm{TC}$ & $239(98.8)$ & $140(79.1)$ & 1.0 & \multirow[t]{2}{*}{0.424} \\
\hline & $\mathrm{TT}$ & $3(1.2)$ & $4(2.3)$ & $0.54[0.12,2.46]$ & \\
\hline \multirow[t]{2}{*}{ Over-dominant } & $\mathrm{CC}, \mathrm{TT}$ & $213(88)$ & $144(81.4)$ & 1.0 & \multirow[t]{2}{*}{0.0594} \\
\hline & $\mathrm{TC}$ & $29(12)$ & $33(18.6)$ & $0.59[0.35,1.02]$ & \\
\hline Log-additive & $0,1,2$ & $242(57.8)$ & $177(42.2)$ & $0.62[0.39,0.98]$ & 0.0402 \\
\hline
\end{tabular}

Table V. Genetic association between rs 12122923 and PCa $(n=442$, adjusted by age).

\begin{tabular}{|c|c|c|c|c|c|}
\hline Model & Genotype & Cases & Controls & OR $(95 \% \mathrm{CI})$ & $p$-Value \\
\hline \multirow[t]{3}{*}{ Codominant } & $\mathrm{C} / \mathrm{C}$ & $221(86.7 \%)$ & $148(79.1 \%)$ & 1.00 & 0.13 \\
\hline & $\mathrm{T} / \mathrm{C}$ & $31(12.2 \%)$ & $35(18.7 \%)$ & $1.74(0.97-3.13)$ & \\
\hline & $\mathrm{T} / \mathrm{T}$ & $3(1.2 \%)$ & $4(2.1 \%)$ & $2.14(0.41-11.21)$ & \\
\hline \multirow[t]{2}{*}{ Dominant } & $\mathrm{C} / \mathrm{C}$ & $221(86.7 \%)$ & $148(79.1 \%)$ & 1.00 & 0.046 \\
\hline & $\mathrm{T} / \mathrm{C}-\mathrm{T} / \mathrm{T}$ & $34(13.3 \%)$ & $39(20.9 \%)$ & $1.78(1.01-3.11)$ & \\
\hline \multirow[t]{2}{*}{ Recessive } & $\mathrm{C} / \mathrm{C}-\mathrm{T} / \mathrm{C}$ & $252(98.8 \%)$ & $183(97.9 \%)$ & 1.00 & 0.43 \\
\hline & $\mathrm{T} / \mathrm{T}$ & $3(1.2 \%)$ & $4(2.1 \%)$ & $1.96(0.38-10.24)$ & \\
\hline \multirow[t]{2}{*}{ Overdominant } & $\mathrm{C} / \mathrm{C}-\mathrm{T} / \mathrm{T}$ & $224(87.8 \%)$ & $152(81.3 \%)$ & 1.00 & 0.071 \\
\hline & $\mathrm{T} / \mathrm{C}$ & $31(12.2 \%)$ & $35(18.7 \%)$ & $1.72(0.96-3.08)$ & \\
\hline Log-additive & - & - & - & $1.65(1.01-2.69)$ & 0.047 \\
\hline
\end{tabular}

dominant model, which showed a similar outcome to the codominant model $(p<0.0548)$ providing a $74 \%$ decreased risk $(\mathrm{OR}=0.26)$ and was associated with a lower grade of prostate cancer. When adjusting for age, the association by the dominant model of inheritance did not remain significant $(p<0.0672)$ (Table VII, dominant model, adjusted by age).

SNPs haplotype analysis. Haplotype analysis of the four IL10 SNPs was evaluated for PCa risk. Pairwise linkage disequilibrium showed an association between all four SNPs; therefore, haplotypes from all four SNPs were analyzed to determine if there was consistency with the individual SNP analyses that were performed. The findings were similar to the individual SNP analyses: compared to the reference haplotype TCCG, only the heterozygous CTTG allele (which included combinations of rs1800871, rs1800893, and rs12122923) was associated with decreased risk of $\mathrm{PCa}(\mathrm{OR}=$ $0.26, p<0.02)$. Odds of PCa decreased by $74 \%$ when comparing CTTG to TCCG (Table VII, model 2). In analyzing haplotypic combinations between rs1800893, rs 12122923, and rs10494879, only TTG $(p<0.05)$ showed an association with PCa risk (Table VIII, model 4). Both rs1800871 and rs12122923 were found associated with a decreased risk of $\mathrm{PCa}$, and since both are in linkage disequilibrium, we cannot determine which one is associated with the disease. Further investigation is needed to determine which of both is a tag SNP and whether it is a representative of the haplotype (25).

To determine the strength of association between the number of copies of the risk allele and Prostate cancer, we used the likelihood ratio test to compare the null allele and ordinal SNP as a factor. All studied SNPs showed a nonlinear relationship between the number of copies of the risk allele and prostate cancer based on a non-significant $p$-value (data not shown).

\section{Discussion}

While the risk factors for PCa are well known, the molecular mechanisms and the genetics underlying the disease are still poorly understood. One such risk factor for $\mathrm{PCa}$ is ethnicity, in which African-American males are not only more likely to develop PCa (26), but there is also a 2.4-times higher risk of death from the disease (27). Chronic inflammation is also considered to play a role in the initiation and progression of the disease (7). The cytokine IL-10 acts to regulate an 
Table VI. Genetic association between SNPs and PCa when adjusted for smoking.

\begin{tabular}{|c|c|c|c|c|c|}
\hline IL-10 SNPs & Genotype & Cases $(\%)$ & Controls (\%) & OR $(95 \% \mathrm{CI})$ & $p$-Value \\
\hline \multicolumn{6}{|l|}{ rs12122923 } \\
\hline \multirow[t]{3}{*}{ Co-dominant } & $\mathrm{CC}$ & 155 (85.6) & 77 (72.6) & 1.0 & 0.0206 \\
\hline & $\mathrm{TC}$ & $23(12.7)$ & $25(23.6)$ & $0.44[0.23]$ & \\
\hline & $\mathrm{TT}$ & $3(1.7)$ & $4(3.8)$ & $0.35[0.08,1.64]$ & \\
\hline \multirow[t]{2}{*}{ Dominant } & $\mathrm{CC}$ & $155(85.6)$ & 77 (72.6) & 1.0 & 0.0056 \\
\hline & $\mathrm{TC}, \mathrm{TT}$ & $26(14.4)$ & $29(27.4)$ & $0.43[0.23,0.78]$ & \\
\hline \multirow[t]{2}{*}{ Recessive } & $\mathrm{CC}, \mathrm{TC}$ & $178(98.3)$ & $102(96.2)$ & 1.0 & 0.254 \\
\hline & TT & $3(1.7)$ & $4(3.8)$ & $0.41[0.09,1.91]$ & \\
\hline \multirow[t]{2}{*}{ Over-dominant } & $\mathrm{CC}, \mathrm{TT}$ & $158(87.3)$ & $81(76.4)$ & 1.0 & 0.0143 \\
\hline & $\mathrm{TC}$ & $23(12.7)$ & $25(23.6)$ & $0.45[0.24,0.85]$ & \\
\hline \multirow{2}{*}{$\begin{array}{l}\text { Log-additive } \\
\text { rs1800871 }\end{array}$} & $0,1,2$ & $181(63.1)$ & $106(36.9)$ & $0.49[0.29,0.83]$ & 0.0066 \\
\hline & & & & & \\
\hline \multirow[t]{2}{*}{ Dominant } & $\mathrm{CC}$ & $62(34.3)$ & $46(43.4)$ & 1.0 & 0.095 \\
\hline & $\mathrm{TC}, \mathrm{TT}$ & $119(65.7)$ & $60(56.6)$ & $1.53[0.93,2.51]$ & \\
\hline \multirow[t]{2}{*}{ Recessive } & $\mathrm{CC}, \mathrm{TC}$ & 155 (85.6) & $98(92.5)$ & 1 & 0.0908 \\
\hline & TT & $26(14.4)$ & $8(7.5)$ & $2.0[0.86,4.6]$ & \\
\hline Log-additive & $0,1,2$ & $181(63.1)$ & $106(36.9)$ & $1.49[1.02,2.18]$ & 0.03901 \\
\hline
\end{tabular}

inflammatory response, and polymorphisms within this gene have been found to affect levels of cytokine expression (28) and associate with PCa risk and severity (13).

Herein, we analyzed the relationship between IL-10 promoter SNPs and PCa risk and severity specifically in African American men, where two SNPs, rs12122923, and rs1800871 found associated with decreased severity. Hovart et al. (14) showed similar results where PCa patients with IL-10-1082 AA genotype had a higher risk of developing PCa with GS $>7$ in Eastern Croatians (14) and North Indians (29). A genome-wide association study in Turkish and Korean cohorts showed a genome-wide significant association between rs1899871 and Behçet's disease (30). This disease and other immune-mediated diseases were found to be associated with increased malignancy risks. However, the relationship between Behçet's disease (BD) and cancer remains unclear (31). Further analysis of rs 1800871 association with immune-mediated disease and cancers is needed to confirm its role in both outcomes.

This study also showed an association between 12122923 and $\mathrm{PCa}$ regardless of smoking status, in which the TC genotype provides a decreased risk of around $50 \%$. When the associations were adjusted for smoking, we found an increased risk of PCa development by 1.6-fold. SNP rs1800871 was also found to result in a 1.5-fold increase in the risk of $\mathrm{PCa}$ development in the presence of the T allele (Table VI). A study authored by Sam S. Oh et al. showed similar findings, where rs1800871 was found to be associated with increased risk of many types of tobacco-related cancers (32).

Gleason score may be used as a measurement for the tumor severity by assigning a numerical value to the biopsy sample $(21,22)$. Of the four SNPs, only rs 1800893 was associated with low Gleason score in which the TC genotype decreases the risk
Table VII. Association between rs1800893 and Gleason score.

\begin{tabular}{lccc}
\hline Model & $\mathrm{N}$ & OR & $p$-Value \\
\hline Co-dominant & & & \\
CC & 17 & 1 & - \\
TC & 23 & 0.24 & 0.0423 \\
TT & 3 & 0.62 & 0.7194 \\
Dominant & & & \\
CC & 17 & 1 & - \\
TC, TT & 26 & 0.26 & 0.0548 \\
Co-dominant adjusted by age & & & \\
CC & 17 & 1 & - \\
TC & 23 & 0.25 & 0.053 \\
TT & 3 & 0.69 & 0.794 \\
Dominant adjusted by age & & & \\
CC & 17 & 1 & - \\
TC, TT & 26 & 0.27 & 0.0672 \\
\hline
\end{tabular}

by $75 \%$, indicating these individuals have a greater chance of developing less severe tumors in the presence of this SNP. The finding that multiple individual SNPs were associated with PCa risk and/or severity gives cause to consider the possibility that certain haplotypes within the IL-10 promoter would also associate with PCa risk. SNP array can become handy to map disease loci and determine the susceptibility genes that are in linkage disequilibrium with IL-10. Furthermore, we conducted a bioinformatics analysis of SNPrelated data from Pca patients provided in the TCGA database. The results revealed that one mutant in IL10 was significantly associated with prostate cancer, specifically, the IL10 R125C mutation, where its oncogenic function is considered unknown. 
Table VIII. Associations between SNPs' haplotypes and PCa.

\begin{tabular}{|c|c|c|c|c|c|c|}
\hline & \multicolumn{3}{|c|}{ Model 1} & \multicolumn{3}{|c|}{ Model 2} \\
\hline & Coef. (Std) & OR & $p$-Value & Coef. (Std) & OR & $p$-Value \\
\hline Intercepts & $0.53(0.23)$ & 1.7 & 0.024 & $-6.89(0.88)$ & 0.0 & 0 \\
\hline \multicolumn{7}{|l|}{ Haplotypes } \\
\hline TCCG (ref) & & 1 & & 1 & 1 & \\
\hline $\mathrm{CCCG}$ & $-0.095(0.21)$ & 0.9 & 0.656 & $0.276(0.25)$ & 1.32 & 0.270 \\
\hline CCTG & $-0.64(0.42)$ & 0.53 & 0.125 & $0.25(0.44)$ & 1.29 & 0.566 \\
\hline CTCG & $-0.183(0.18)$ & 0.83 & 0.309 & $0.038(0.205)$ & 1.04 & 0.852 \\
\hline CTTG & $-0.65(0.42)$ & 0.52 & 0.126 & $-1.35(0.58)$ & 0.26 & 0.021 \\
\hline TTCG & $0.72(0.51)$ & 2.06 & 0.162 & $0.997(0.56)$ & 2.71 & 0.074 \\
\hline Rare $<3 \%$ & $-0.118(0.35)$ & 0.89 & 0.734 & $0.38(0.38)$ & 1.47 & 0.321 \\
\hline Age & & & & $0.111(0.012)$ & 1.12 & 0.0 \\
\hline \multirow[t]{3}{*}{ loglike } & -279.74 (8df) & $-220.14(7 d f)$ & & & & \\
\hline & \multicolumn{2}{|c|}{ Model 3} & \multicolumn{2}{|c|}{ Model 4} & & \\
\hline & Coef. (Std) & $p$-Value & Coef. (Std) & $p$-Value & & \\
\hline Intercepts & $0.44(1.64)$ & 0.008 & $-6.4(0.8)$ & 0.00 & & \\
\hline \multicolumn{7}{|l|}{ CCG (ref) } \\
\hline CTG & $-0.51(0.4)$ & 0.202 & $0.04(0.488)$ & 0.925 & & \\
\hline TCG & $-0.03(0.15)$ & 0.82 & $0.04(0.17)$ & 0.794 & & \\
\hline TTG & $-0.53(0.4)$ & 0.197 & $-1.12(0.57)$ & 0.05 & & \\
\hline Rare $<0.03$ & $-0.13(0.34)$ & 0.707 & $0.24(0.37)$ & 0.517 & & \\
\hline Age & & & $0.106(0.01)$ & 0.00 & & \\
\hline
\end{tabular}

Models 1 and 2 involve rs1800871 and rs1800893, rs12122923 and rs10494879. Models 3 and 4 involve rs1800893, rs12122923 and rs10494879.

Two haplotypes were associated with the risk of developing PCa. The CTTG haplotype at all four SNP loci resulted in a $74 \%$ decreased risk while the haplotype TTG for rs1800893, rs12122923, and rs1049479 was associated with increased PCa risk. A meta-analysis conducted by Zhang et al. showed that one of our SNPs (rs1800871) is part of a common haplotype in the promoter for IL-10 that is associated with increased cancer risk in Caucasian and in non-Caucasians (33). Determining an association between these individual SNPs and haplotypes to the development and severity of PCa implies that IL-10 may play a role in the biology of PCa. Dysregulation of cytokines may be linked to the incidence and clinical course of malignant diseases with the development of acute or chronic inflammatory reactions at tumor sites (34). IL-10 is a multifunctional cytokine with both immunosuppressive and anti-angiogenic functions, consequently resulting in both tumor-promoting and tumorinhibiting properties (35). Results from this study suggest that IL-10 promoter polymorphisms might be a risk factor for PCa development in subjects who smoke and may contribute to high-grade cancers which may impact PCa progression in African American patients. A study conducted in Indians with PCa showed a strong association between SNPs and haplotypes in interleukin 10 and the aggressiveness of Pca.
The association increased when lifestyle habits including smoking were considered in the study (36). Determining IL10 genotypes and haplotypes along with smoking history may help establish screening and prevention programs based on a stratification of the disease risk in the high risk African American male population.

\section{Conflicts of Interest}

The Authors have no conflicts of interest to disclose.

\section{Authors' Contributions}

MA, TM, GD, and HB contributed to the design and implementation of the research; AI, MK, YK, BW, LR, and MA participated in data acquisition and analysis; VA performed the statistical analysis; MA and $\mathrm{HB}$ wrote the manuscript.

\section{Acknowledgements}

The Authors would like to thank all the participants who took part in this study. The Authors acknowledge funding for this study from the National Institutes of Health (S06 GM08016 and RR03048) and grant \#G12 MD007597 from NIMHD, NIH to the RCMI program at Howard University. 


\section{References}

1 DeSantis CE, Miller KD, Goding Sauer A, Jemal A and Siegel RL: Cancer statistics for African Americans, 2019. CA Cancer J Clin 69: 211-233, 2019. PMID: 30762872. DOI: 10.3322/caac.21555

2 Wilson BD, Ricks-Santi LJ, Mason TE, Abbas M, Kittles RA, Dunston GM and Kanaan YM: Admixture mapping links RACGAP1 regulation to prostate cancer in African Americans. Cancer Genomics Proteomics 15: 185-191, 2018. PMID: 29695400. DOI: 10.21873/cgp. 20076

3 Kidd LR, Coulibaly A, Templeton TM, Chen W, Long LO, Mason T, Bonilla C, Akereyeni F, Freeman V, Isaacs W, Ahaghotu C and Kittles RA: Germline BCL-2 sequence variants and inherited predisposition to prostate cancer. Prostate Cancer Prostatic Dis 9: 284-292, 2006. PMID: 16733517. DOI: 10.1038/sj.pcan.4500884

4 Gurel B, Lucia MS, Thompson IM, Goodman PJ, Tangen CM, Kristal AR, Parnes HL, Hoque A, Lippman SM, Sutcliffe S, Peskoe SB, Drake CG, Nelson WG, De Marzo AM and Platz EA: Chronic inflammation in benign prostate tissue is associated with high-grade prostate cancer in the placebo arm of the prostate cancer prevention trial. Cancer Epidemiol Biomarkers Prev 23: 847-856, 2014. PMID: 24748218. DOI: 10.1158/10559965.EPI-13-1126

5 Mason TE, Ricks-Santi L, Chen W, Apprey V, Joykutty J, Ahaghotu C, Kittles R, Bonney G and Dunston GM: Association of CD14 variant with prostate cancer in African American men. Prostate 70: 262269, 2010. PMID: 19830784. DOI: 10.1002/pros.21060

6 Hanahan D and Weinberg RA: Hallmarks of cancer: the next generation. Cell 144: 646-674, 2011. PMID: 21376230. DOI: 10.1016/j.cell.2011.02.013

7 De Marzo AM, Nakai Y and Nelson WG: Inflammation, atrophy, and prostate carcinogenesis. Urol Oncol 25: 398-400, 2007. PMID: 17826659. DOI: 10.1016/j.urolonc.2007.05.007

8 De Marzo AM, Platz EA, Sutcliffe S, Xu J, Grönberg H, Drake CG, Nakai Y, Isaacs WB and Nelson WG: Inflammation in prostate carcinogenesis. Nat Rev Cancer 7: 256-269, 2007. PMID: 17384581 . DOI: $10.1038 /$ nrc2090

9 Zadka L, Kram P, Koscinski J, Jankowski R, Kaczmarek M, Piatek K, Kulus M, Gomułkiewicz A, Piotrowska A and Dziegiel P: Association between interleukin-10 receptors and the CD45immunophenotype of central nervous system tumors: a preliminary study. Anticancer Res 37: 5777-5783, 2017. PMID: 28982901. DOI: 10.21873/anticanres.12019

10 Iyer SS and Cheng G: Role of interleukin 10 transcriptional regulation in inflammation and autoimmune disease. Crit Rev Immunol 32: 23-63, 2012. PMID: 22428854. DOI: 10.1615/critrevimmunol.v32.i1.30

11 Vinod C, Jyothy A, Vijay Kumar M, Raman RR, Nallari P and Venkateshwari A: A common SNP of IL-10 (-1082A/G) is associated with increased risk of premenopausal breast cancer in south Indian women. Iran J Cancer Prev 8, 2015. PMID: 26478792. DOI: $10.17795 / \mathrm{ijcp}-3434$

12 Banday MZ, Balkhi HM, Sameer AS, Chowdri NA and Haq E: Strong association of interleukin-6 $-174 \mathrm{G} / \mathrm{C}$ promoter single nucleotide polymorphism with a decreased risk of colorectal cancer in ethnic Kashmiri population: A case control study. Tumour Biol 39: 1010428317695940, 2017. PMID: 28349833. DOI: $10.1177 / 1010428317695940$

13 Faupel-Badger JM, Kidd LC, Albanes D, Virtamo J, Woodson K and Tangrea JA: Association of IL-10 polymorphisms with prostate cancer risk and grade of disease. Cancer Causes Control 19: 119-124, 2008. PMID: 26753456. DOI: 10.1007/s10552-0079077-6

14 Horvat V, Mandic S, Marczi S, Mrcela M and Galic J: Association of IL-1beta and IL-10 Polymorphisms with prostate cancer risk and grade of disease in eastern Croatian population. Coll Antropol 39: 393-400, 2015. PMID: 26753456.

15 Wang MH, Helzlsouer KJ, Smith MW, Hoffman-Bolton JA, Clipp SL, Grinberg V, De Marzo AM, Isaacs WB, Drake CG, Shugart YY and Platz EA: Association of IL10 and other immune response- and obesity-related genes with prostate cancer in CLUE II. Prostate 69: 874-885, 2009. PMID: 19267370. DOI: 10.1002/pros.20933

16 Dluzniewski PJ, Wang MH, Zheng SL, De Marzo AM, Drake CG, Fedor HL, Partin AW, Han M, Fallin MD, Xu J, Isaacs WB and Platz EA: Variation in IL10 and other genes involved in the immune response and in oxidation and prostate cancer recurrence. Cancer Epidemiol Biomarkers Prev 21: 1774-1782, 2012. PMID: 22859398. DOI: 10.1158/1055-9965.EPI-12-0458

17 Liu J, Song B, Bai X, Liu W, Li Z, Wang J, Zheng Y and Wang Z: Association of genetic polymorphisms in the interleukin-10 promoter with risk of prostate cancer in Chinese. BMC Cancer 10: 456-456, 2010. PMID: 20735825. DOI: 10.1186/1471-2407-10456

18 Raja J, Ramachandran N, Munneke G and Patel U: Current status of transrectal ultrasound-guided prostate biopsy in the diagnosis of prostate cancer. Clin Radiol 61: 142-153, 2006. PMID:16439219. DOI: 10.1016/j.crad.2005.10.002

19 Gleason DF: Histologic grading of prostate cancer: a perspective. Hum Pathol 23: 273-279, 1992. PMID: 1555838. DOI: 10.1016/0046-8177(92)90108-f

20 Humphrey PA: Gleason grading and prognostic factors in carcinoma of the prostate. Mod Pathol 17: 292-306, 2004. PMID: 14976540. DOI: $10.1038 /$ modpathol.3800054

21 Ham WS, Chalfin HJ, Feng Z, Trock BJ, Epstein JI, Cheung C, Humphreys E, Partin AW and Han M: New prostate cancer grading system predicts long-term survival following surgery for Gleason score 8-10 prostate cancer. Eur Urol 71: 907-912, 2017. PMID: 27876305. DOI:10.1016/j.eururo.2016.11.006

22 Humphrey PA, Moch H, Cubilla AL, Ulbright TM and Reuter VE: The 2016 WHO classification of tumours of the urinary system and male genital organs-part B: Prostate and bladder tumours. Eur Urol 70: 106-119, 2016. PMID: 26996659. DOI: 10.1016/ j.eururo.2016.02.028

23 Sherry ST, Ward MH, Kholodov M, Baker J, Phan L, Smigielski EM and Sirotkin K: dbSNP: the NCBI database of genetic variation. Nucleic Acids Res 29: 308-311, 2001. PMID: 11125122. DOI: $10.1093 /$ nar/29.1.308

24 Barrett JC: Haploview: Visualization and analysis of SNP genotype data. Cold Spring Harb Protoc 2009: pdb.ip71, 2009. PMID: 20147036. DOI: 10.1101/pdb.ip71

25 Ding K and Kullo IJ: Methods for the selection of tagging SNPs: a comparison of tagging efficiency and performance. Eur J Hum Genet 15: 228-236, 2007. PMID: 17164795. DOI: 10.1038/ sj.ejhg. 5201755

26 Daremipouran MR, Beyene D, Apprey V, Naab TJ, Kassim OO, Copeland RL and Kanaan YM: The association of a novel identified VDR SNP with prostate cancer in African American men. Cancer Genomics Proteomics 16: 245-255, 2019. PMID: 31243105. DOI: $10.21873 / \operatorname{cgp} .20129$ 
27 Chornokur G, Dalton K, Borysova ME and Kumar NB: Disparities at presentation, diagnosis, treatment, and survival in African American men, affected by prostate cancer. Prostate 71: 985-997, 2011. PMID: 21541975. DOI: 10.1002/pros.21314

28 Gibson AW, Edberg JC, Wu J, Westendorp RG, Huizinga TW and Kimberly RP: Novel single nucleotide polymorphisms in the distal IL-10 promoter affect IL-10 production and enhance the risk of systemic lupus erythematosus. J Immunol 166: 3915-3922, 2001. PMID: 11238636. DOI: 10.4049/jimmunol.166.6.3915

29 Kesarwani P, Ahirwar DK, Mandhani A, Singh AN, Dalela D, Srivastava AN and Mittal RD: IL-10-1082 G>A: a risk for prostate cancer but may be protective against progression of prostate cancer in North Indian cohort. World J Urol 27: 389-396, 2009. PMID: 19145440. DOI: 10.1007/s00345-008-0361-1

30 Mizuki N, Meguro A, Ota M, Ohno S, Shiota T, Kawagoe T, Ito N, Kera J, Okada E, Yatsu K, Song Y, Lee E, Kitaichi N, Namba K, Horie Y, Takeno M, Sugita S, Mochizuki M, Bahram S, Ishigatsubo $\mathrm{Y}$ and Inoko $\mathrm{H}$ : Genome-wide association studies identify IL23R-IL12RB2 and IL10 as Behçet's disease susceptibility loci. Nat Genet 42: 703-706, 2010. PMID: 20622879. DOI: 10.1038/ng.624

31 Jung YS, Han M, Kim DY, Cheon JH and Park S: Cancer risk in Korean patients with Behçet's disease: A nationwide populationbased study. PLoS One 12: e0190182, 2017. PMID: 29287101. DOI: 10.1371/journal.pone.0190182

32 Oh SS, Chang S, Cai L, Cordon-Cardo C, Ding B, Greenland S, He N, Jiang Q, Kheifets L, Le A, Lee YA, Liu S, Lu M, Mao JT, Morgenstern H, Mu L, Pantuck A, Papp JC, Park SL, Rao JY, Reuter VE, Tashkin DP, Wang H, You NY, Yu S, Zhao J, Belldegrun A and Zhang Z: Single nucleotide polymorphisms of 8 inflammation-related genes and their associations with smokingrelated cancers. Int J Cancer 127: 2169-2182, 2010. PMID: 20112337. DOI: $10.1002 /$ ijc. 25214
33 Zhang K, Zhang L, Wang X and Zhang L: The IL-10 promoter haplotype and cancer risk: evidence from a meta-analysis. Fam Cancer 11: 313-319, 2012. PMID: 22644143. DOI: 10.1007/ s10689-012-9533-7

34 Baraldi-Junkins CA, Beck AC and Rothstein G: Hematopoiesis and cytokines. Relevance to cancer and aging. Hematol Oncol Clin North Am 14: 45-61, viii, 2000. PMID: 10680071. DOI: 10.1016/s0889-8588(05)70277-X

35 Sato T, Terai M, Tamura Y, Alexeev V, Mastrangelo MJ and Selvan SR: Interleukin 10 in the tumor microenvironment: a target for anticancer immunotherapy. Immunol Res 51: 170-182, 2011. PMID: 22139852. DOI: 10.1007/s12026-011-8262-6

36 Bandil K, Singhal P, Dogra A, Rawal SK, Doval DC, Varshney AK and Bharadwaj M: Association of SNPs/haplotypes in promoter of TNF A and IL-10 gene together with life style factors in prostate cancer progression in Indian population. Inflamm Res 66: 10851097, 2017. PMID: 28993831 DOI: 10.1007/s00011-017-1088-5
Received November 7, 2019

Revised November 27, 2019

Accepted December 2, 2019 